\title{
Kinetics of structure formation of a composite mortar with nano- additives based on aluminium
}

\author{
S.Yu. Efremova ${ }^{1, *}$, M.I. Panfilova ${ }^{2}$, N.I. Zubrev ${ }^{3}$, and O.V. Novoselova ${ }^{2}$ \\ ${ }^{1}$ Penza State Technological University, 440039, 1a/11, pr. Baidukova/ul. Gagarina, Penza, Russia \\ ${ }^{2}$ National Research University Moscow State University of Civil Engineering, 129337, 26, Yaroslavskoye Shosse, Moscow, Russia \\ ${ }^{3}$ Russian University of Transport, 125190, 22/2, Chasovaya str., Moscow, Russia
}

\begin{abstract}
This paper discusses the possibility of using aluminum-containing nano-additives as structure modifiers of composite mortar in order to ensure safety and durability of rubble foundation. Higher injection efficiency can be achieved by integrating the composite mortar into the foundation body. The temporal evolution of structure formation in composite mortar with various contents of boehmite and aluminosilicate nanotubes (ANT) was studied. The optimal concentrations of additives were determined at which the rate of structure formation reaches its maximum. It was revealed that ANT additives accelerate the hardening time of the composite mortar by 1.3 times in comparison with boehmite additives. The greatest impact on accelerating the structure formation in the initial period is achieved by adding $0.125 \%$ aluminosilicate tubes to the mass of cement. It was found that in this case, the duration of flowability loss of the composite mortar is reduced by a factor of three compared with that of the control sample.
\end{abstract}

\section{Introduction}

Grouting mortars are widely used to fill old mine workings or large underground cavities arising from filtration of underground water while building structures in complicated geological and hydrogeological conditions. During elimination of karst processes, it is necessary to achieve the maximum artificial filling of voids in order to stop groundwater filtration and reinforce the mass of karst rocks. Prevention of water access in them can be achieved by injecting liquid glass, cement clay or bitumen into cracks and voids, since the traditional mixtures used to eliminate underground voids are of insignificant strength. Therefore, mixtures with reinforcing element are used as grouting mortar [1-3].

According to the "Forecast of the Long-Term SocioEconomic Development of the Russian Federation for the Period Until 2030" (developed by the Ministry of Economic Development of the Russian Federation), creation of new building materials that take into account modern economic and environmental requirements is the main task of the building materials industry on the longterm horizon.

Grouting mortars with nanotubes (microscopic hollow tubes of several atomic layers of carbon polymers) can be used as such compositions. It is known that many promising areas in construction deal with aluminum-containing nanoparticles [4-9].

The aim of this work is to examine the hardening processes of a composite solution with aluminum-based nano-additives.
We used the 500 grade cement, P2T2A bentonite, which has a high content of montmorillonite $(70 \%)$ and a high exchange capacity $(113.3 \mathrm{mg} \cdot \mathrm{eq} / 100 \mathrm{~g})$, boehmite additives which are nanocrystalline modifiers (3D$\mathrm{NCM}$ ), and aluminosilicate nanotubes. The watercement ratio was $2: 1$. The content of nano-additives varied from 0 to $1 \%$ by weight of cement [10].

Boehmite has an orthorhombic crystal structure with the following dimensions of unit cells: $\mathrm{a}=2.87, \mathrm{~b}=12.23, \mathrm{c}=3.70 \AA$ (Fig. 1 ).

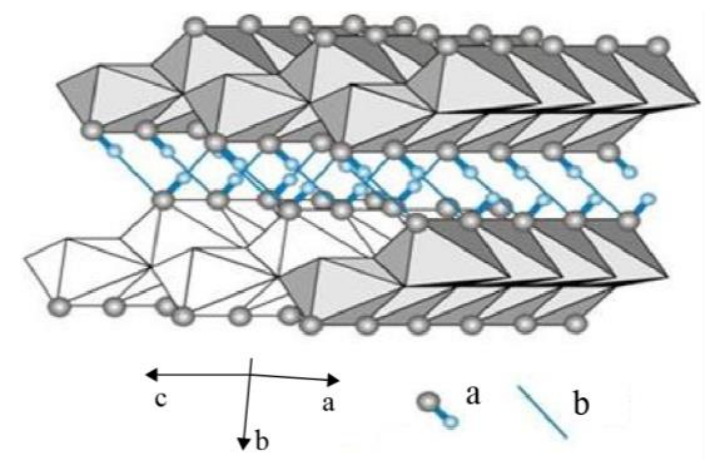

Fig. 1. Boehmite structure: a-OH; b-Hydrogen bond.

The structure of boehmite corresponds to the formula $\mathrm{AlOOH}$. The main technological properties of boehmite are shown in Fig. 2 [11-18].

\footnotetext{
* Corresponding author: author@e-mail.org
} 


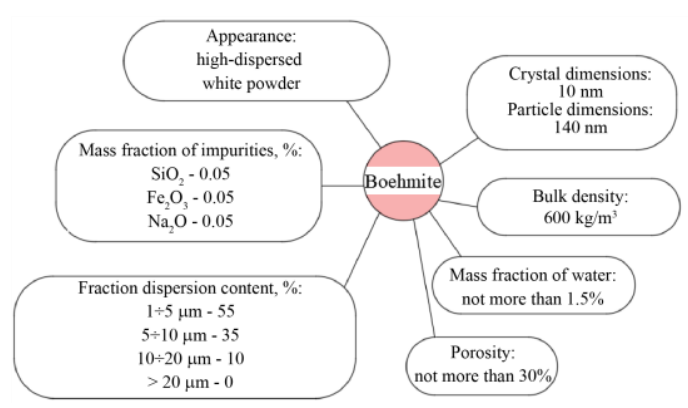

Fig. 2. Main technological properties of boehmite.

The dispersed composition of boehmite mainly consists of the 1-5 $\mu \mathrm{m}$ fraction, so addition of such a modifier to the composite system can lead to accelerated hydration and a denser packing of cement stone due to the filling of voids.

Aluminosilicate nanotubes (ANT) are hollow tubes with internal diameter of $15 \mathrm{~nm}$ and external diameter of about $50 \mathrm{~nm}$. The wall twisted into a spiral consists of single atomic layers of aluminosilicate, and its thickness can be 20-30 layers, the chemical composition of which, in addition to water, includes silicon and aluminum oxides. Their content reaches $75 \%$.

The high catalytic ability of these tubes can be explained by the presence of negatively charged aluminum oxide on the inner surface, and positively charged silicon oxide on the outer surface (Fig. 3).

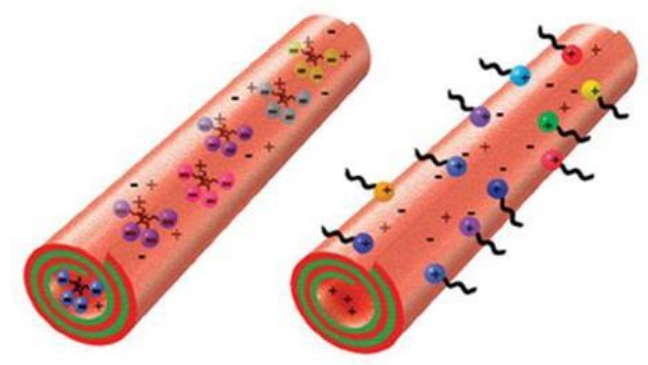

Fig. 3. ANT structure.

The time of sedimentation or hardening is one of the most important technological properties of grouting mortars, since the mortar in a more or less homogeneous state must be delivered (injected) in the desired time interval. The hardening time of composite solution is usually determined by geological and hydrological conditions of soils being settled, and under normal conditions it should be about one hour (according to the Russian State Standard GOST 10178-76).

We studied the temporal evolution of structure formation in composite mortars with various contents of boehmite and ANT. A composite mortar was prepared by mixing bentonite with water additives with further addition of cement and water glass to it. The changes in strength were examined during hardening time. The change in plastic strength was determined using the Rebinder device with a cone every 10 minutes within three hours.

Fig. 4 shows the kinetics of structure formation of the composite mortar as a function of boehmite content in the mixture.

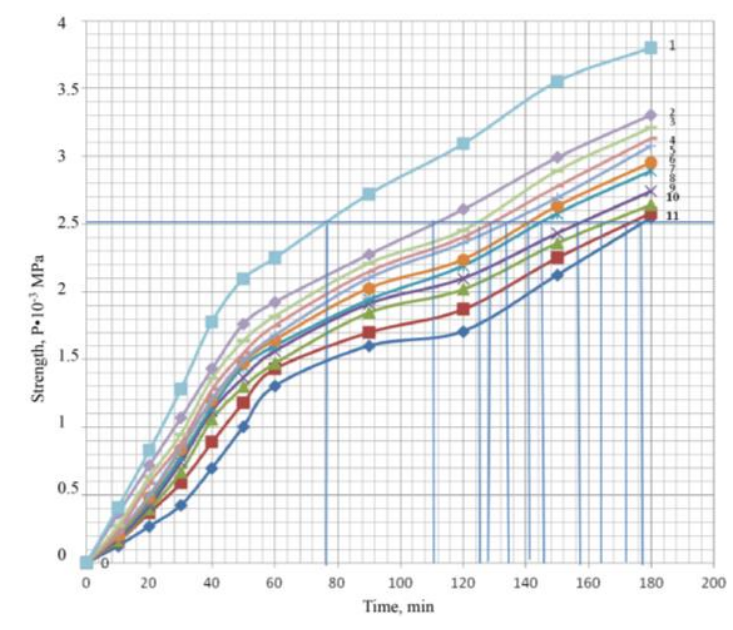

Fig. 4. The strength of composite mortars based on $\mathrm{P}_{2} \mathrm{~T}_{2} \mathrm{~A}$ bentonite as a function of the storage duration for various boehmite contents, $\%$ by weight of cement: $1-0.208 ; 2-1.000$; 3 - $0.700 ; 4-0.600 ; 5-0.352 ; 6-0.306 ; 7-0.249 ; 8-0.133 ; 9$ $0.100 ; 10-0.041 ; 11-0.000$.

The setting time of composite mixture was determined by the intersection of curves shown in figure, with the straight line corresponding to the strength of flowability loss, namely $2.5 \cdot 10^{-3} \mathrm{MPa}$.

The greatest decrease in setting time was noted for addition of $0.208 \%$ by weight of cement, which corresponds to hardening time of approximately 75 minutes (Fig. 5) (according to the Russian State Standard GOST 10178-76).

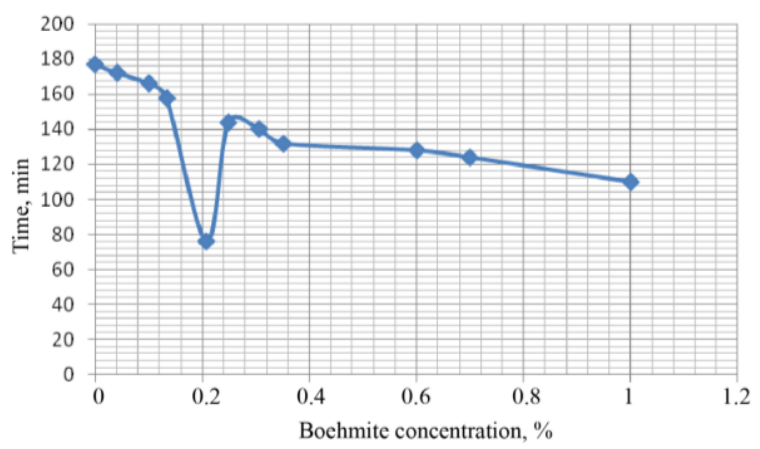

Fig. 5. Relationship between the hardening time and boehmite concentration in the mixture.

The increase in the rate of structure formation with addition of $0.2 \%$ boehmite can be explained by the fact that the optimal ratio of its microparticles match the spaces of cement stone.

The influence of aluminosilicate tube additives were studied in a similar way. The obtained data are shown in Fig.6. 


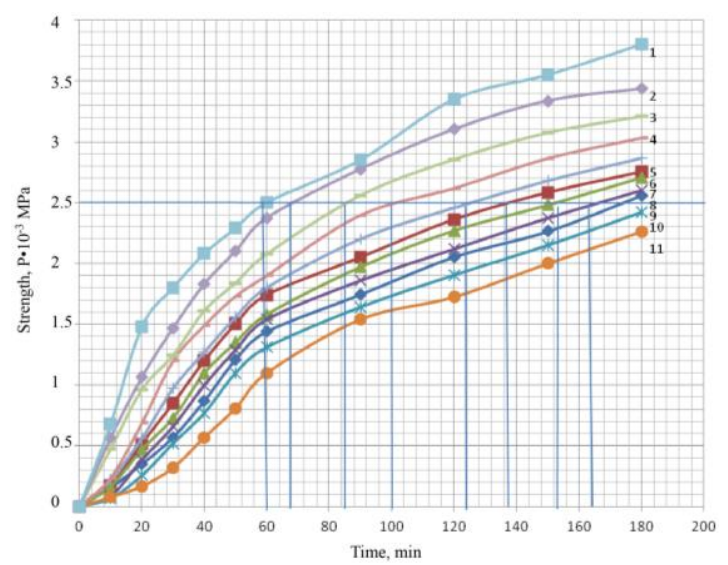

Fig. 6. The kinetics of strength change of composite mortar for various ANT contents, $\%$ by weight of cement $1-0.125 ; 2$ $0.100 ; 3-0.150 ; 4-0.250 ; 5-0.080 ; 6-0.300 ; 7-0.075 ; 8$ $0.450 ; 9-0.006 ; 10-0.400 ; 11-0.000$.

Analysis of data from Fig. 6 shows that the smallest setting time for the composite mortar is 60 minutes, which is achieved with an additive content of $0.125 \%$. Moreover, this indicator decreases almost three times in comparison with a sample that does not contain aluminosilicate tubes (Fig. 7).

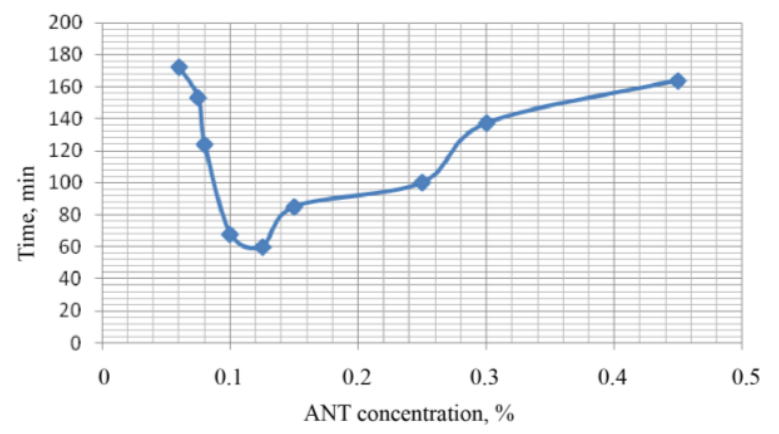

Fig. 7. Relationship between the hardening time and ANT concentration in the mixture.

Thus it was found that nano-additives accelerate the hydration of clinker constituents of cement, which leads to acceleration of structure formation of composite mortars and, as a result, to reduction in their flowability loss time [19-23].

The optimal concentrations of additives were determined at which the rate of structure formation reaches its maximum. It was revealed that additions of ANT concentrations accelerate the hardening time of composite mortar by 1.3 times in comparison with that with boehmite.

It was found that the greatest accelerating of structure formation in the initial period is achieved when aluminosilicate tubes in the amount of $0.125 \%$ of cement mass are added. Probably, this can be explained by the peculiarities of their structure, which provides the greatest adhesion during hydration in the area of cement stone formation.

It was concluded that the highest rate of structure formation is achieved at an optimal concentration of ANT of $0.125 \%$ by weight of cement. Thus, to ensure the industrial safety of underground structures, the use of composite mortar with the addition of ANT in the amount of $0.125 \%$ by weight of cement can be recommended.

\section{References}

[1] M.V. Ustinova, N.I. Zubrev, M.I. Panfilova, et al., Obtaining composite mortar with the addition of ash from the combustion of spent sleepers, Ecology and industry of Russia, 22, 5, 36-40 (2018).

[2] S.Y. Efremova, N.I. Zubrev, M.I. Panfilova, T.V. Matveyeva, Composite systems using ash from burning production waste, IOP Conference Series: Earth and Environmental Science, 337, 1, 012034 (18 November 2019).

[3] M.I. Panfilova, N.I. Zubrev, M.V. Fomina, Modified composite systems, Internet-vestnik VolgGASU, 2, 33, 9 (2014).

[4] S.Ya. Brichka, Natural aluminosilicate nanotubes: structure and properties, Nanostrukturnoye materialovedeniye, 2, 40-53 (2009).

[5] L.Yu. Kotel, A.V. Brichka, A.L. Petranovskaya, S.Ya. Brichka, X-ray analysis of galloisite nanotubes modified with cerium (IV) oxide, II AllUkrainian conference for young scientists "Modern materials science: materials and technologies", Kiev, 125 (2001).

[6] M.I. Panfilova, Physico-chemical properties of foamed clay cement systems (Abstract of $\mathrm{PhD}$ Tech. Thesis. Tver, 32, 2004).

[7] M.I. Panfilova, M.V. Fomina, Issues on increasing the strength characteristics using injection mortars, International scientific and technical conference "Innovative technologies in the construction and training of industrial engineering personnel", Proceedings of the II regional scientific and practical seminar, Smolensk, 314 (2011).

[8] A.F. Buryanov, Efficient gypsum materials and products using ultrafine aluminosilicate additives and carbon nanomodifiers (Abstract of D.Sc. in engineering Thesis, Moscow, 38, 2012).

[9] M.I. Panfilova, N.I. Zubrev, V.P. Gorbachevskii, S.Y. Efremova, The renewal of the bearing capacity of rubble masonry by the composite mortar, IOP Conf. Series: Journal of Physics: Conf. Series, 1425, 012068 (2020).

[10] M.I. Panfilova, N.I. Zubrev, S.Y. Efremova, M.I. Yahkind, V.P. Gorbachevskii, Strengthening of water-saturated soils of the bases of underground structures with composite mortar modified by industrial waste, boehmite Journal: Case Studies in Construction Materials, 12, e00323 (2020).

[11] V.P. Chalyi, Metal hydroxides. Regularities of formation, composition, structure and properties: monograph (Kiev: Naukova Dumka, 160, 1972). 
[12] D. Shelley, D. Smale, A.J. Tulloch, Boehmite in syenite from NewZealand, Mineralogical Magazine, 41, 398-400 (1977).

[13] A.B. Bukhalo, Non-autoclave heat-insulating foam-gas concrete with nanodispersed modifiers (Abstract of $\mathrm{PhD}$ Tech. Thesis, Belgorod, 27, 2010).

[14] V.V. Nazarov, O.B. Pavlova-Verevkina, Synthesis and colloid-chemical properties of boehmite hydrosols, Colloid Journal, 60, 6, 797-807 (1998).

[15] M.S. Akselrod, Optically stimulated luminescence of Al2O3, Radiat. Meas., 29, 391-399 (1996).

[16] S. Sakka, Handbook of sol-gel science and technology processing characterization and applications (Clawer academic publishers Boston, $680,2005)$.

[17] R.W. Jones, Sol preparation of ceramic and glasses, Metal and Materials, 4, 12, 748-751 (1988).

[18] Y. Lvov, W. Wang, L. Zhang, R. Fakhrullin, Halloysite Clay Nanotubes for Loading and Sustained Release of Functional Compounds, Adv. Mater, 28, 6, 1227-1250 (2016).

[19] X. Zhang, Q. Li, T.G Holesinger, Ultrastrong, stiff, and lightweight carbon-nanotube fibers, Advanced Materials, 19, 23, 4198-4201 (2007).

[20] J.E. Riggs, Z.X. Guo, D.L. Carroll, Y.P. Sun, Strong luminescence of solubilized carbon nanotubes, Journal of American Chemical Society, 122, 24, 5879-5880 (2000).

[21] K.P.D. Jong, J.W. Geus, Carbon nanofibers: catalytic synthesis and applications, Catalysis Review: Science Engineering, 42, 4, 481-510 (2000).

[22] M. Panfilova, N. Zubrev, O. Novoselova, S. Efremova, Composite grouting mortar based on 3D-NKM - Nanocrystalline inoculant, MATEC Web of Conferences, 196 (2018).

[23] M.I. Panfilova, N.I. Zubrev, O.V. Novoselova, C.Y. Efremova, Comparative analysis of strength characteristics of grouting mortars, XXI International scientific conference on advanced in civil engineering construction, 365 (2018). 